\title{
ROLL versus RSL: toss of a coin?
}

\author{
M. Ahmed • M. Douek
}

Received: 4 June 2013/ Accepted: 9 June 2013/Published online: 23 June 2013

(C) Springer Science+Business Media New York 2013

\begin{abstract}
The safety and benefits of radio-guided localization (RGL) versus wire-guided localization (WGL) surgery in the treatment of non-palpable breast cancers have been confirmed through several meta-analyses. RGL has become the standard of care in several institutions, although overall uptake has been slow. In view of this evidence supporting RGL, we believe that the future discussion is not of RGL versus WGL, but rather of what form of RGL will constitute best practice of care going forward. We therefore discuss the case for radio-guided occult lesion localization versus radioactive seed localization in the treatment of non-palpable breast cancers, is it really a toss of a coin?
\end{abstract}

Keywords Wire-guided localization - Radio-guided occult lesion localization - ROLL - Radioactive seed localization · RSL · Radio-guided localization ·

Non-palpable breast cancer

Non-palpable breast cancers constitute approximately onethird of all diagnosed breast cancers, [1] therefore creating a heavy burden upon health care systems. The current accepted standard of treatment for non-palpable breast cancers of wire-guided localization (WGL) has been increasingly challenged by radio-guided localization (RGL) techniques in the form of radio-guided occult lesion

M. Ahmed $(\bowtie) \cdot$ M. Douek

Department of Research Oncology, King's College London,

Guy's Hospital Campus, Great Maze Pond, London SE1 9RT,

UK

e-mail: muneer.ahmed@kcl.ac.uk

M. Douek

e-mail: michael.douek@kcl.ac.uk localization (ROLL) and radio-guided seed localization (RSL). In the four meta-analyses of RGL versus WGL, [25] three have demonstrated the superiority of RGL [2, 4, 5] with the remaining study demonstrating shorter operating times but also greater volume excisions for RGL [3]. However, the clinical relevance of this greater volume of excision remains questionable [6]. The two largest cohort series [7-9] each composed of approximately 1,000 patients supports the excellent outcomes achievable with RGL. The economical assessment has also demonstrated no disadvantage for RGL [7, 9-11]. In view of the mounting evidence supporting RGL, the question no longer remains that of the previous decade in terms of deciding between RGL and WGL, but rather the clinically relevant issue has now progressed to deciding between ROLL and RSL in the treatment of non-palpable breast cancers.

Both techniques depend upon the presence of a skilled radiologist to perform either ultrasound or stereotactically guided localization, with the administration of between 0.2 and $0.5 \mathrm{~mL}$ of ${ }^{99 \mathrm{~m}} \mathrm{Tc}$-radiolabelled albumin-based colloid for ROLL or a single $8 \times 0.4 \mathrm{~mm}$ titanium seed radiolabelled with ${ }^{125} \mathrm{I}$ in RSL. Great variation exists in the radiation dose administered for ROLL, with the literature quoting anywhere between 5 and $123 \mathrm{MBq},[12,13]$ whilst for RSL it is between 3.7 and $10.7 \mathrm{MBq}[14,15]$. ROLL requires localization to be performed within $24 \mathrm{~h}$ of surgery due to the short $6 \mathrm{~h}$ half-life of ${ }^{99 \mathrm{~m}} \mathrm{Tc}$-labelled colloid and RSL typically is performed $0-5$ days prior to surgery [7, 14-17]. In the primary systemic therapy (PST) setting RSL can be undertaken several months before surgery because the half-life of ${ }^{125} \mathrm{I}$ is 60 days [18]. This flexibility in the timing of seed insertion provides a clear advantage by reducing the pressure upon scheduling conflicts between the radiology department and operating theatres, and therefore resource management on the day of 
surgery [2]. However, since RSL requires the insertion of a device into the lesion, it is important to ensure that the indications of use include lesion localization.

No studies in the published literature have demonstrated a significant difference between the complications of ROLL and RSL compared to WGL, demonstrating that both techniques are extremely safe. Concern has been raised at the issue of migration and subsequent loss of inserted seeds, but clinically relevant seed migration is rare and has been reported in $<1 \%$ of RSL procedures [19]. In the eight published studies [7, 14-18, 20] on RSL, 2 studies $[11,17]$ have failed to demonstrate $100 \%$ successful intraoperative localization for RSL, with failure rates of $2 \%$ [11] and $7.9 \%$. [17] The largest published series of RSL with 978 patients recorded a $100 \%$ successful localization rate [7]. However, this remains an important issue requiring the establishment of a defined protocol to allow the safe handling of the seeds from intake in the nuclear medicine department, through sterilization, implantation, excision and removal. Errors at any point along this chain can convert a controlled procedure to a potentially dangerous one and result in temporary closure of RSL programmes until resolved [11]. Twenty-nine studies have been published on ROLL [8, 12, 13, 21-46] and nine of these studies $[8,12,23-26,39,45,46]$ failed to achieve a $100 \%$ intraoperative localization rate, with failure rates being recorded between $0.4 \%$ [8] and $4.5 \%$, [12] with the figure of $0.4 \%$ being from the largest published series of ROLL with 959 patients [8].

A potential benefit of RSL is that ${ }^{125} \mathrm{I}$ emits $27 \mathrm{keV}$ gamma rays compared to ${ }^{99} \mathrm{Tc}$ which emits $140 \mathrm{keV}$. This means that by altering the sensitivity on the gamma probe it is possible to differentiate between radioactive emissions from the localized lesion and the sentinel lymph nodes irrespective of the site of the primary lesion, although the benefit of this has not been confirmed in RCTs. The range for successful identification of the sentinel lymph node for RSL is between $96.8 \%$ [14] and $100 \%$ [15, 16], whereas, the same figure for ROLL is between $84.9 \%$ [28] and $100 \%[12,22,37]$. This would suggest a trend towards favouring RSL for successful sentinel lymph node biopsy (SLNB) over ROLL. In a similar fashion, the administration of different radioisotopes for lesion localization and SLNB could allow for varied energy threshold settings on the probe to differentiate between radioactive emissions from the lesion itself or sentinel lymph nodes in ROLL. The possibility of using two radioisotopes such as ${ }^{99 \mathrm{~m}} \mathrm{Tc}$ and ${ }^{111} \mathrm{I}$ could potentially improve surgical outcomes although it has only been applied successfully in vitro [47] and in upper limb drainage studies [48] and not been clinically applied to ROLL.

Due to current financial constraints in world healthcare systems, it is very important to consider the economic impact of these two techniques. However, to date no detailed health economic assessment has been performed for RSL. The large cohort study by McGhan et al. [7] involving $>1,000$ patients demonstrated that the material costs for performing RSL were one-third of the cost for WGL (US 60 vs. Us 170). This is largely due to the large series of patients undergoing RSL at the institution, which can consequently order seeds in large bulk reducing costs, but the additional time required for the nuclear medicine department to process, sterilize and package the seeds is not taken into account in this calculation. This would mean that in units performing smaller case numbers, the savings on material costs would not be as significant and costs between RSL and WGL would be similar [11]. Postma et al. [10] in their comprehensive cost-benefit analysis of their randomized controlled trial (RCT) of ROLL versus WGL [45] found that there was no economic difference between ROLL and WGL when considered overall in terms of costs associated with morbidity and re-operation rates. Interestingly, they found that ROLL cost $€ 0$ in terms of localization because it allowed radioisotope injection for SLNB to be performed concurrently with localization as opposed to WGL which required an additional procedure to localization. In this respect, ROLL is better than RSL, which also requires a separate radioisotope injection by the nuclear medicine department in order to perform SLNB.

The issue of a learning curve associated with ROLL and RSL has never been formally assessed within the published evidence. However, the largest two cohort series for RSL and ROLL, [7, 8] each comprising nearly 1,000 patients did not suggest the presence of a significant learning curve. This suggests that both techniques are intuitive and the necessary skills easily acquired. Most importantly, the resemblance of RSL and ROLL to the performance of SLNB which is a standard practice means that breast surgeons who have never performed either technique formally will still be familiar with the principles and possess the necessary skills to learn both techniques rapidly. Certainly studies comparing RSL and ROLL to WGL have suggested that surgeons favoured the radio-guided techniques over WGL in terms of ease of performance [17, 46].

The only study in the literature to compare ROLL against RSL found no significant difference in clinical outcomes between the 2 techniques. The study by Donker et al. [49] consisted of 154 patients (RSL; $n=71$, ROLL; $n=83$ ) and compared the 2 techniques in the context of patients undergoing breast-conserving surgery after PST. Whilst there was no significant difference in clinical outcomes, there was a clear logistical benefit to ${ }^{125} \mathrm{I}$ seed localization. The ${ }^{125} \mathrm{I}$ seed was able to be introduced radiologically into the tumour before commencing PST and the patient did not require any further radiological intervention. This is in contrast to the ROLL group which 
required the insertion of a radiopaque marker before commencing PST and then another radiological procedure within $24 \mathrm{~h}$ of scheduled surgery to have the injection of radiolabelled nanocolloid. Although the economical implications of this were not explored in the study in view of no differences in morbidity between the two techniques being identified, a reduction in radiology suite attendance would inevitably lead to financial benefits favouring RSL. An issue not addressed for this study was the issue of SLNB. All patients underwent SLNB prior to commencing PST and therefore did not undergo repeat SLNB on completion of PST. This meant that at the time of breast-conserving surgery being performed, the administration of ${ }^{99 \mathrm{~m}}$ Tc for SLNB was not necessary. In the case of the ROLL group, technically SLNB could have been performed after the intra-tumoral injection of ${ }^{99 \mathrm{~m}} \mathrm{Tc}$ for lesion localization, but in the case of RSL an additional procedure would have been necessary for ${ }^{99 \mathrm{~m}} \mathrm{Tc}$ injection. Therefore, the benefit of one less radiology attendance in RSL may only be confined to PST patients and not the more general treatment of the $35 \%$ of patients [1] who present with nonpalpable breast cancers and require axillary staging in the form of SLNB at the time of breast-conserving surgery.

Level I evidence from meta-analyses exists to support the use of RGL in the treatment of non-palpable breast cancer [2-5]. This evidence has accumulated over the last 15 years since the first publication of the ROLL technique [9]. The debate of RGL versus WGL is now a discussion, which should be best left in the past. The future discussion should consider which form of RGL is most beneficial and how can RGL be refined and improved further. It can be demonstrated from what has been presented from the published evidence that it is not possible to identify any differences in clinical outcomes including complications between ROLL and RSL to suggest the superiority of one over the other. Both techniques have proven to be competitively priced in comparison with WGL $[7,10,11]$ and to have no significant learning curves for surgeons $[7,8$, 17, 46]. The single area where a difference can be identified currently is in terms of the flexibility and timing of RSL over ROLL. RSL has a clear benefit in aiding scheduling of surgery due to the flexibility of time over which seed localization by the radiologist can occur $[7,14$ 17]. By allowing this flexibility in timing as opposed to being confined to within $24 \mathrm{~h}$ of surgery as in ROLL it is possible to ensure greater inter-departmental efficiency and reduce delays, particularly with a timely start to the first operating case of the day. The study by Donker et al. [49] comparing ROLL and RSL in the PST setting suggested the benefit of one less radiology appointment for RSL, but this was in the context of isolated SLNB before definitive breast conservation surgery. This therefore does not take into account the necessity for an injection of ${ }^{99 \mathrm{~m}} \mathrm{Tc}$ before surgery in RSL for SLNB. In fact it may be the case, that ROLL with its single injection of ${ }^{99 \mathrm{~m}} \mathrm{Tc}$ for localization and SLNB proves more beneficial economically. Therefore, before assuming any benefits we need them formally assessed and this can only be achieved by running adequately powered RCTs comparing the two techniques. Despite these benefits, it must be remembered that no matter what benefits are demonstrated in any future RCTs of ROLL versus RSL, there will always be a limitation in uptake of RGL and that will be due to limited radioisotope accessibility. This has always been the case with SLNB and due to radioisotope dependence SLNB is only available to $60 \%$ of patients in the developed world [50] and almost negligible uptake in the rest of the world [51]. With this in mind, the future may not lie in RGL itself, but rather techniques, which possess the advantages of RGL but without the disadvantages of radioisotopes. Such a possibility may lie in the use of superparamagnetic iron-oxide nanoparticles (SPIONs) which have been successfully applied to SLNB [52]. These SPIONs have similar particle sizes to nanocolloids used in ROLL and could potentially be used for a SLNB and concurrent localization procedure. If this was the case, then the final obstruction of RGL uptake would have been conquered and the benefits of the technique finally accessible to the largest possible demographic.

Conflict of interest The authors have no disclosures to make concerning financial and personal relationships with other people or organizations that could inappropriately influence their work.

\section{References}

1. Lovrics PJ, Cornacchi SD, Farrokhyar F, Garnett A, Chen V, Franic S, Simunovic M (2009) The relationship between surgical factors and margin status after breast-conservation surgery for early stage breast cancer. Am J Surg 197(6):740-746

2. Ahmed M, Douek M (2013) Radioactive seed localisation (RSL) in the treatment of non-palpable breast cancers: systematic review and meta-analysis. Breast [Epub ahead of print]

3. Ahmed M, Douek M (2013) Systematic review of radioguided versus wire-guided localization in the treatment of non-palpable breast cancers. Breast Cancer Res Treat (in press)

4. Lovrics PJ, Cornacchi SD, Vora R, Goldsmith CH, Kahnamoui K (2011) Systematic review of radioguided surgery for non-palpable breast cancer. Eur J Surgical Oncol 37(5):388-397

5. Sajid MS, Parampalli U, Haider Z, Bonomi R (2012) Comparison of radioguided occult lesion localization (ROLL) and wire localization for non-palpable breast cancers: a meta-analysis. J Surg Oncol 105(8):852-858

6. Ahmed M, Douek M (2013) What is the clinical significance of the volume of tissue excised in ROLL? Breast Cancer Res Treat

7. McGhan LJ, McKeever SC, Pockaj BA, Wasif N, Giurescu ME, Walton HA, Gray RJ (2011) Radioactive seed localization for nonpalpable breast lesions: review of 1,000 consecutive procedures at a single institution. Ann Surg Oncol 18(11):3096-3101 
8. Monti S, Galimberti V, Trifiro G, De Cicco C, Peradze N, Brenelli F, Fernandez-Rodriguez J, Rotmensz N, Latronico A, Berrettini A et al (2007) Occult breast lesion localization plus sentinel node biopsy (SNOLL): experience with 959 patients at the European Institute of Oncology. Ann Surg Oncol 14(10):2928-2931

9. Luini A, Zurrida S, Paganelli G, Galimberti V, Sacchini V, Monti S, Veronesi P, Viale G, Veronesi U (1999) Comparison of radioguided excision with wire localization of occult breast lesions. Br J Surg 86(4):522-525

10. Postma EL, Koffijberg H, Verkooijen HM, Witkamp AJ, van den Bosch MA, van Hillegersberg R (2013) Cost-effectiveness of radioguided occult lesion localization (ROLL) versus wire-guided localization (WGL) in breast conserving surgery for nonpalpable breast cancer: results from a randomized controlled multicenter trial. Ann Surg Oncol 20(7):2219-2226

11. Rao R, Moldrem A, Sarode V, White J, Amen M, Rao M, Andrews V, Euhus D, Radford L, Ulissey M (2010) Experience with seed localization for nonpalpable breast lesions in a public health care system. Ann Surg Oncol 17(12):3241-3246

12. Kim J, Chung D, Spillane A (2004) Combined radioguided occult lesion and sentinel node localization for breast cancer. ANZ J Surg 74(7):550-553

13. van Rijk MC, Tanis PJ, Nieweg OE, Loo CE, Olmos RA, Oldenburg HS, Rutgers EJ, Hoefnagel CA, Kroon BB (2007) Sentinel node biopsy and concomitant probe-guided tumor excision of nonpalpable breast cancer. Ann Surg Oncol 14(2):627-632

14. Gray RJ, Salud C, Nguyen K, Dauway E, Friedland J, Berman C, Peltz E, Whitehead G, Cox CE (2001) Randomized prospective evaluation of a novel technique for biopsy or lumpectomy of nonpalpable breast lesions: radioactive seed versus wire localization. Ann Surg Oncol 8(9):711-715

15. Hughes JH, Mason MC, Gray RJ, McLaughlin SA, Degnim AC, Fulmer JT, Pockaj BA, Karstaedt PJ, Roarke MC (2008) A multisite validation trial of radioactive seed localization as an alternative to wire localization. Breast J 14(2):153-157

16. Gray RJ, Pockaj BA, Karstaedt PJ, Roarke MC (2004) Radioactive seed localization of nonpalpable breast lesions is better than wire localization. Am J Surg 188(4):377-380

17. Lovrics PJ, Goldsmith CH, Hodgson N, McCready D, Gohla G, Boylan C, Cornacchi S, Reedijk M (2011) A multicentered, randomized, controlled trial comparing radioguided seed localization to standard wire localization for nonpalpable, invasive and in situ breast carcinomas. Ann Surg Oncol 18(12):3407-3414

18. Gobardhan PD, de Wall LL, van der Laan L, ten Tije AJ, van der Meer DC, Tetteroo E, Poortmans PM, Luiten EJ (2013) The role of radioactive iodine-125 seed localization in breast-conserving therapy following neoadjuvant chemotherapy. Ann Oncol 24(3):668-673

19. Barentsz MW, van den Bosch MA, Veldhuis WB, van Diest PJ, Pijnappel RM, Witkamp AJ, Verkooijen HM (2013) Radioactive seed localization for non-palpable breast cancer. Br J Surg 100(5):582-588

20. van Riet YE, Jansen FH, van Beek M, van de Velde CJ, Rutten HJ, Nieuwenhuijzen GA (2010) Localization of non-palpable breast cancer using a radiolabelled titanium seed. Br J Surg 97(8):1240-1245

21. Audisio RA, Nadeem R, Harris O, Desmond S, Thind R, Chagla LS (2005) Radioguided occult lesion localisation (ROLL) is available in the UK for impalpable breast lesions. Ann R Coll Surg Engl 87(2):92-95

22. Barros A, Cardoso MA, Sheng PY, Costa PA, Pelizon C (2002) Radioguided localisation of non-palpable breast lesions and simultaneous sentinel lymph node mapping. Eur J Nucl Med Mol Imaging 29(12):1561-1565

23. Belloni E, Canevari C, Panizza P, Marassi A, Rodighiero M, Tacchini S, Zuber V, Sassi I, Gianolli L, Fazio F et al (2011)
Nonpalpable breast lesions: preoperative radiological guidance in radioguided occult lesion localisation (ROLL). Radiol Med (Torino) 116(4):564-574

24. Besic N, Kramaric A, Podnar B, Perhavec A, Music M, GrazioFrkovic S, Zgajnar J (2009) Factors correlated to successful surgical treatment of 181 non-palpable invasive breast carcinomas. Breast 18(5):294-298

25. Chow MP, Hung WK, Chu T, Lui CY, Ying M, Mak KL, Chan M (2011) Isotope-guided surgery for nonpalpable breast cancer. World J Surg 35(1):165-169

26. Chu TY, Lui CY, Hung WK, Kei SK, Choi CL, Lam HS (2010) Localisation of occult breast lesion: a comparative analysis of hookwire and radioguided procedures. \#\#\#\#\#\#\#\#\#Hong Kong medical journal $=$ Xianggang yi xue za zhi / Hong Kong Academy of Medicine 16(5):367-372

27. Donker M, Straver ME, Rutgers EJ, Valdes Olmos RA, Loo CE, Sonke GS, Wesseling J, Vrancken Peeters MJ (2012) Radioguided occult lesion localisation (ROLL) in breast-conserving surgery after neoadjuvant chemotherapy. Eur J Surg Oncol 38(12):1218-1224

28. Feggi L, Basaglia E, Corcione S, Querzoli P, Soliani G, Ascanelli S, Prandini N, Bergossi L, Carcoforo P (2001) An original approach in the diagnosis of early breast cancer: use of the same radiopharmaceutical for both non-palpable lesions and sentinel node localisation. Eur J Nucl Med 28(11):1589-1596

29. Gallegos-Hernandez JF, Tanis PJ, Nieweg OE, Duerloo E, Valdes-Olmos R, Rutgers EJ, Kroon BB (2003) Radioguided surgery for therapeutic excision of nonpalpable breast cancer. Cirugia $y$ cirujanos 71(6):421-426

30. Giacalone PL, Bourdon A, Trinh PD, Taourel P, Rathat G, Sainmont M, Perocchia H, Rossi M, Rouleau C (2012) Radioguided occult lesion localization plus sentinel node biopsy (SNOLL) versus wire-guided localization plus sentinel node detection: a case control study of 129 unifocal pure invasive nonpalpable breast cancers. Eur J Surg Oncol 38(3):222-229

31. Lavoue V, Nos C, Clough KB, Baghaie F, Zerbib E, Poulet B, Lefrere Belda MA, Ducellier A, Lecuru F (2008) Simplified technique of radioguided occult lesion localization (ROLL) plus sentinel lymph node biopsy (SNOLL) in breast carcinoma. Ann Surg Oncol 15(9):2556-2561

32. Medina-Franco H, Abarca-Perez L, Garcia-Alvarez MN, UlloaGomez JL, Romero-Trejo C, Sepulveda-Mendez J (2008) Radioguided occult lesion localization (ROLL) versus wire-guided lumpectomy for non-palpable breast lesions: a randomized prospective evaluation. J Surg Oncol 97(2):108-111

33. Moreno M, Wiltgen JE, Bodanese B, Schmitt RL, Gutfilen B, da Fonseca LM (2008) Radioguided breast surgery for occult lesion localization-correlation between two methods. J Exp Clin Cancer Res 27:29

34. Nadeem R, Chagla LS, Harris O, Desmond S, Thind R, Titterrell C, Audisio RA (2005) Occult breast lesions: a comparison between radioguided occult lesion localisation (ROLL) vs. wireguided lumpectomy (WGL). Breast 14(4):283-289

35. Ocal K, Dag A, Turkmenoglu O, Gunay EC, Yucel E, Duce MN (2011) Radioguided occult lesion localization versus wire-guided localization for non-palpable breast lesions: randomized controlled trial. Clinics 66(6):1003-1007

36. Paredes P, Vidal-Sicart S, Zanon G, Roe N, Rubi S, Lafuente S, Pavia J, Pons F (2008) Radioguided occult lesion localisation in breast cancer using an intraoperative portable gamma camera: first results. Eur J Nucl Med Mol Imaging 35(2):230-235

37. Patel A, Pain SJ, Britton P, Sinnatamby R, Warren R, Bobrow L, Barber RW, Peters AM, Purushotham AD (2004) Radioguided occult lesion localisation (ROLL) and sentinel node biopsy for impalpable invasive breast cancer. Eur J Surg Oncol 30(9):918-923 
38. Ronka R, Krogerus L, Leppanen E, von Smitten K, Leidenius M (2004) Radio-guided occult lesion localization in patients undergoing breast-conserving surgery and sentinel node biopsy. Am J Surg 187(4):491-496

39. Sarlos D, Frey LD, Haueisen H, Landmann G, Kots LA, Schaer G (2009) Radioguided occult lesion localization (ROLL) for treatment and diagnosis of malignant and premalignant breast lesions combined with sentinel node biopsy: a prospective clinical trial with 100 patients. Eur J Surg Oncol 35(4):403-408

40. Takacs T, Paszt A, Simonka Z, Abraham S, Borda B, Ottlakan A, Ormandi K, Lazar M, Voros A, Kahan Z et al (2013) Radioguided occult lesion localisation versus wire-guided lumpectomy in the treatment of non-palpable breast lesions. Pathol Oncol Res 19(2):267-273

41. Tanis PJ, Deurloo EE, Valdes Olmos RA, Rutgers EJ, Nieweg OE, Besnard AP, Kroon BB (2001) Single intralesional tracer dose for radio-guided excision of clinically occult breast cancer and sentinel node. Ann Surg Oncol 8(10):850-855

42. Thind CR, Desmond S, Harris O, Nadeem R, Chagla LS, Audisio RA (2005) Radio-guided localization of clinically occult breast lesions (ROLL): a DGH experience. Clin Radiol 60(6):681-686

43. Zgajnar J, Besic N, Frkovic-Grazio S, Hocevar M, Vidergar B, Rener M, Lindtner J (2003) Radioguided excision of the nonpalpable breast cancer and simultaneous sentinel lymphnode biopsy using a single radiopharmaceutical: an original approach to accurate administration of the blue dye. J Surg Oncol 83(1):48-50

44. Mariscal Martinez A, Sola M, de Tudela AP, Julian JF, Fraile M, Vizcaya S, Fernandez J (2009) Radioguided localization of nonpalpable breast cancer lesions: randomized comparison with wire localization in patients undergoing conservative surgery and sentinel node biopsy. AJR Am J Roentgenol 193(4):1001-1009
45. Postma EL, Verkooijen HM, van Esser S, Hobbelink MG, van der Schelling GP, Koelemij R, Witkamp AJ, Contant C, van Diest PJ, Willems SM et al (2012) Efficacy of 'radioguided occult lesion localisation' (ROLL) versus ‘wire-guided localisation' (WGL) in breast conserving surgery for non-palpable breast cancer: a randomised controlled multicentre trial. Breast Cancer Res Treat 136(2):469-478

46. Rampaul RS, Bagnall M, Burrell H, Pinder SE, Evans AJ, Macmillan RD (2004) Randomized clinical trial comparing radioisotope occult lesion localization and wire-guided excision for biopsy of occult breast lesions. Br J Surg 91(12):1575-1577

47. Haigh PI, Glass EC, Essner R (2000) Accuracy of gamma probes in localizing radioactivity: in vitro assessment and clinical implications. Cancer Biother Radiopharm 15(6):561-569

48. Britton TB, Solanki CK, Pinder SE, Mortimer PS, Peters AM, Purushotham AD (2009) Lymphatic drainage pathways of the breast and the upper limb. Nucl Med Commun 30(6):427-430

49. Donker M, Drukker CA, Valdes Olmos RA, Rutgers EJ, Loo CE, Sonke GS, Wesseling J, Alderliesten T, Vrancken Peeters MJ (2013) Guiding breast-conserving surgery in patients after neoadjuvant systemic therapy for breast cancer: a comparison of radioactive seed localization with the ROLL technique. Ann Surg Oncol

50. Rescigno J, Zampell JC, Axelrod D (2009) Patterns of axillary surgical care for breast cancer in the era of sentinel lymph node biopsy. Ann Surg Oncol 16(3):687-696

51. Leong SP, Shen ZZ, Liu TJ, Agarwal G, Tajima T, Paik NS, Sandelin K, Derossis A, Cody H, Foulkes WD (2010) Is breast cancer the same disease in Asian and Western countries? World J Surg 34(10):2308-2324

52. Douek $M$ et al (2010) SentiMag Multicentre Trial (NIHR) UKCRN ID12178 